\title{
Paléontologie humaine (2008-2011)
}

\section{Michel Brunet}

\section{OpenEdition}

\section{Journals}

Édition électronique

URL : https://journals.openedition.org/annuaire-cdf/16054

DOI : 10.4000/annuaire-cdf.16054

ISBN : 978-2-7226-0572-5

ISSN : 2109-9227

Éditeur

Collège de France

Édition imprimée

Date de publication : 30 décembre 2020

Pagination : 626

ISBN : 978-2-7226-0516-9

ISSN : 0069-5580

Référence électronique

Michel Brunet, «Paléontologie humaine (2008-2011) », L'annuaire du Collège de France [En ligne], 118 2020, mis en ligne le 01 avril 2021, consulté le 22 août 2022. URL : http://journals.openedition.org/ annuaire-cdf/16054 ; DOI : https://doi.org/10.4000/annuaire-cdf.16054 
PALÉONTOLOGIE HUMAINE (2008-2011)

Michel BRUNET

Professeur émérite

Mots-clés : paléontologie humaine

\section{RECHERCHE : ORIGINE ET ÉVOLUTION DE LA FAMILLE HUMAINE DURANT LE MIO-PLIOCÈNE}

Poursuite de l'étude du matériel fossile: mis au jour durant les campagnes de fouilles conduites au nord du Tchad (désert du Djourab), depuis 25 années par la MPFT (Mission paléoanthropologique franco-tchadienne), en collaboration avec l'université (département de paléontologie) et le CNRD (service des collections paléontologiques) de N'Djamena. Pour l'année 2017-2018, ces recherches sont à l'origine, entre autres, de deux publications autour de Sahelanthropus tchadensis, dit « Toumaï », le plus ancien d'entre nous (ca. $7 \mathrm{Ma}$ ) :

- «The earliest known Hominin limb bones remains (late Miocene, 7 Ma, Djurab desert, Chad) » (pour soumission à Nature) ;

- «Dietary ecology of Sahelanthropus tchadensis (Chadian Late Miocene hominin) from stable carbon isotopes » (review in ScienceDirect).

Prospections géologiques et paléontologiques : «Origine des Anthropoïdes sudaméricains », Terres australes (Patagonie chilienne \& continent Antarctique), mission de terrain toujours en préparation ; «À la chasse aux chimpanzés fossiles (jusque-là inconnus à l'état fossile) sur les hauts plateaux du Cameroun de l'Ouest », mission de terrain, 23 avril-25 mai 2018.

Co-organisation du colloque au Collège de France « Nouvelles perspectives pour l'histoire de l'humanité » (3 et 4 juillet 2018), et co-auteur de deux communications.

\section{Publication}

BRUnet M., D'Abel à Toumaï. Nomade, chercheur d'os, Paris, Odile Jacob, 2018. 